\title{
Digging deeper into obesity
}

\author{
Rexford S. Ahima \\ Department of Medicine, Division of Endocrinology, Diabetes and Metabolism, and the Institute for Diabetes, Obesity and Metabolism, \\ University of Pennsylvania School of Medicine, Philadelphia, Pennsylvania, USA.
}

\begin{abstract}
The growing problem of obesity is associated with multiple morbidities, including increased risk of diabetes, hypertension, heart disease, sleep apnea, and cancer. Obesity promotes disability, decreases productivity, and shortens life span. Although much attention has been focused on diet and exercise, these strategies alone are not effective in preventing obesity and maintaining weight loss. Moreover, the development of pharmacological approaches for obesity treatment has been dogged by poor efficacy and serious side effects. The biology of obesity is very complex, and mechanisms linking obesity to various diseases are poorly understood. This issue of the JCI highlights important concepts in our understanding of the pathogenesis of obesity and its complications.
\end{abstract}

\section{Introduction}

Obesity is characterized by excessive fat accumulation in adipose tissue and other organs. The BMI, calculated as weight $(\mathrm{kg})$ divided by height squared $\left(\mathrm{m}^{2}\right)$, is used as a measurement of body fat in clinical and epidemiologic studies. The National Heart, Lung, and Blood Institute and the World Health Organization (WHO) define overweight as a BMI equal to or greater than $25 \mathrm{~kg} / \mathrm{m}^{2}$ and obese as a BMI equal to or greater than $30 \mathrm{~kg} / \mathrm{m}^{2}(1,2)$. The BMI criteria for Asia and Oceania are slightly different: overweight is a BMI equal to or greater than $23 \mathrm{~kg} / \mathrm{m}^{2}$ and obesity is a BMI equal to or greater than $25 \mathrm{~kg} / \mathrm{m}^{2}$ (3). Children with a BMI greater than the 97 th percentile in regard to age and sex are considered obese, and those with a BMI greater than the 90th percentile but less than the 97th percentile are considered overweight (4).

\section{A growing epidemic}

The WHO estimated that in 2008, 1.5 billion adults aged 20 years and older were overweight and over 200 million men and 300 million women - approximately $10 \%$ of adults - were obese. In 2010, about 43 million children under five years of age were overweight (5). Obesity is no longer a problem for high-income developed countries alone. Indeed, the largest increases in obesity since 1980 have occurred in low- and middle-income countries, particularly in urban settings in Oceania, Latin America, and North Africa (Figure 1 and refs. 6, 7). While body fat content is undoubtedly influenced by genetics and maternal as well as perinatal factors, the recent global upsurge in obesity is due to a shift in diet toward energy-dense foods rich in fat and sugars but low in vitamins and other micronutrients $(6,7)$. There have been drastic increases in total calorie intake over the past two decades (Figure 2 and ref. 8). Epidemiologic data indicate that chronic intake of fatty diets and fructose and frequent consumption of fast food increase the risk of obesity (9-14). This is evident in developing countries where indigenous diets rich in vegetables, fruits, and fish have been replaced by cheaper and more energydense Western diets $(15,16)$.

Sedentary lifestyle is also a major contributor to weight gain (17-20). Data from the National Health and Nutrition Examination Survey (NHANES) show a close relationship between low levels of physical activity and weight gain in both men and

Conflict of interest: The author has declared that no conflict of interest exists. Citation for this article: J Clin Invest. 2011;121(6):2076-2079. doi:10.1172/JCI58719. women (17). Prolonged television watching is highly predictive of obesity and diabetes risk in adults and children $(19,20)$. Global changes in diet and physical inactivity have been fueled by changes in agricultural practices, food processing, marketing and distribution, transportation, and other aspects of urban planning. Collectively, this "obesogenic environment" predisposes to diabetes, cardiovascular disease, osteoarthritis, sleep apnea, cancer, and other ailments (21-23). Type 2 diabetes and cardiovascular diseases, once thought to occur only in adults, are now seen in obese children $(24,25)$. Ironically, developing countries, which have been saddled with communicable diseases and undernutrition for generations, are now facing an upsurge of obesity and its adverse health consequences. In low- and middle-income countries, malnutrition has become a double-headed monster. It is not uncommon to find undernutrition co-existing with obesity, especially in urban settings (26-28). Increased consumption of energy-dense Western diets in conjunction with reduced physical activity have led to sharp increases in obesity and diabetes in Polynesia, North Africa, the Middle East, Latin America, and other developing countries (26-28).

Diet, exercise, and other lifestyle modifications are logical steps for preventing and treating obesity. However, the common experience tells us that it is very easy to gain but difficult to lose weight (29). The recidivism rate for regain of weight to pre-weight loss levels is very high. Anti-obesity drugs are largely ineffective, and even bariatric surgery - an approach that provides great and rapid reduction in weight - is still followed by substantial weight regain over time (30). Thus, there is an urgent need for understanding of the regulation of energy homeostasis and how obesity causes diabetes and other complications.

\section{Layers of complexity}

This issue of the JCI features reviews on crucial aspects of obesity and related disorders. Sadaf Farooqi and Shwetha Ramachandrappa (31) discuss monogenic syndromes, rare chromosomal abnormalities, and complex population genetics that have provided evidence for molecular interactions between the brain and other organs as well as a biological basis for eating behaviors associated with obesity. The discovery of leptin was a major milestone in our understanding of the molecular regulation of energy homeostasis (32). Leptin is secreted by adipocytes and acts on the hypothalamus to inhibit food intake, increase energy expenditure, and reduce body fat. Leptin also regulates reproduction, immunity, intermediary metabolism, 
A

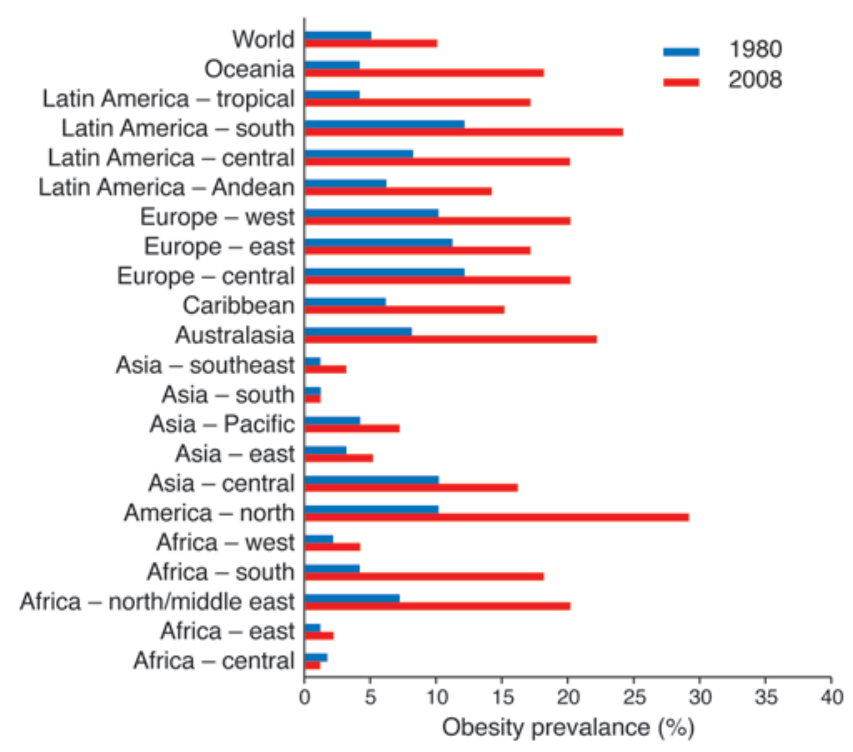

B

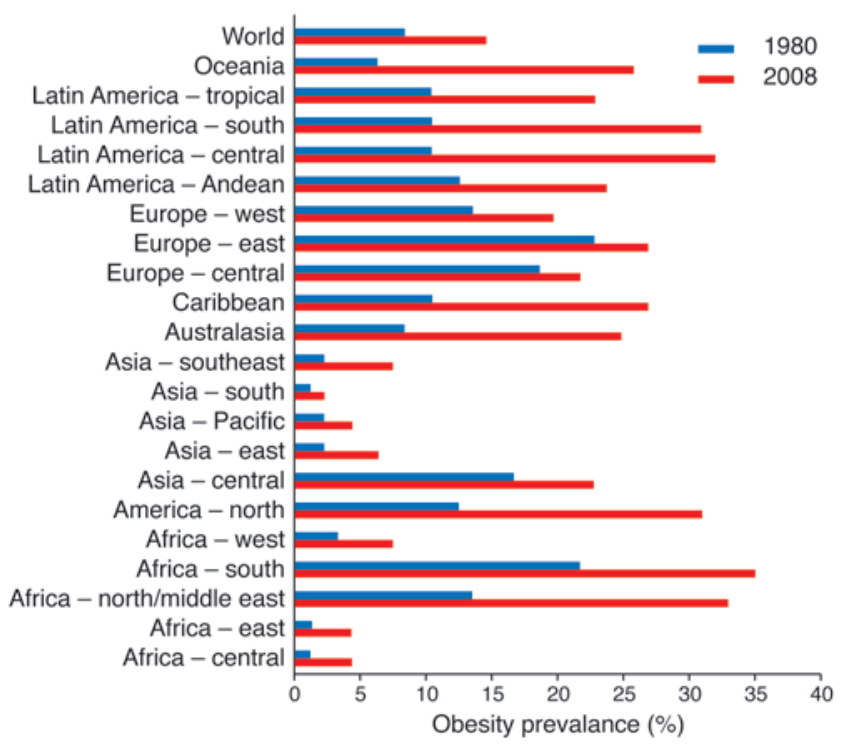

Figure 1

Worldwide change in prevalence of obesity in men (A) and women (B) between 1980 and 2008. Adapted with permission from Lancet (6).

and bone biology, indicating a crucial role in integration of nutrition, normal cellular physiology, and pathological states. Laurent Gautron and Joel Elmquist (33) review seminal studies preceding the identification of leptin and discuss advances in our understanding of the diverse actions of leptin since its discovery.

Sun and colleagues (34) discuss the adaptation of adipose tissue in obesity. Adipose tissue is composed of triglyceride-filled cells (adipocytes), adipocyte precursors and other stromal cells, resident and infiltrating immune cells, and an extensive collagen network and blood supply. Proteins secreted by adipocytes (adipokines) act locally to regulate adipose tissue expansion and signal to various organs to control feeding, energy balance, and neuroendocrine and other functions. Dysregulation of adipose biology in obesity is associated with ectopic fat deposition (steatosis), insulin resistance, diabetes, cardiovascular complications, and other diseases.

Lipid droplets store neutral lipids in various cells. The surface of each lipid droplet is coated with proteins of the perilipin family, which regulate lipid metabolism under normal conditions and mediate excess accumulation of intracellular lipids associated with obesity, diabetes, and atherosclerosis. Greenberg et al. (35) discuss the distribution patterns, regulation, and functions of these lipid droplet proteins and their putative roles in obesity, steatosis, inflammation, insulin sensitivity, and organ dysfunction.

Obesity results in significant alterations in components of the immune system in multiple

Figure 2 organs. As described by Carey Lumeng and Alan Saltiel (36), this leads to inflammatory changes in adipose tissue, liver, pancreatic islets, blood vessels, and hypothalamus. Changes in the levels of cytokines, chemokines, and activation states of different types of

\section{A DES total (calories/day), 1980}

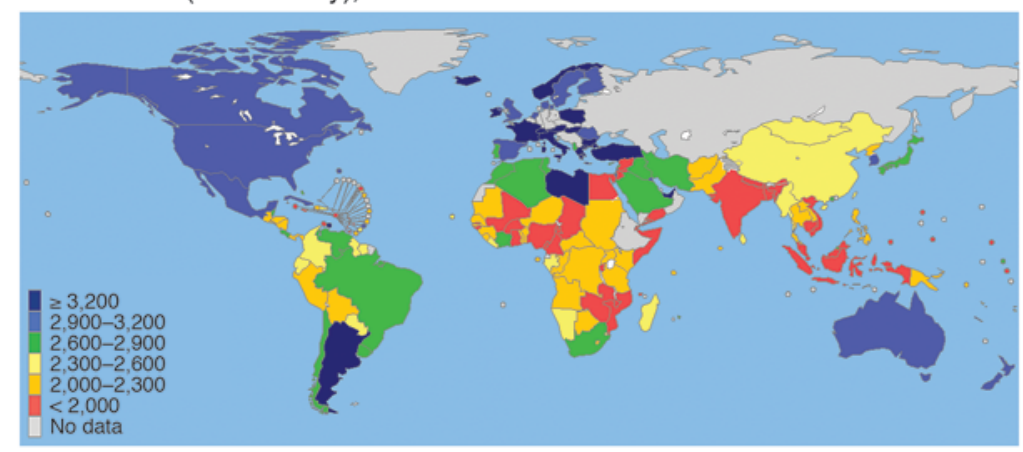

B DES total (calories/day), most recent data

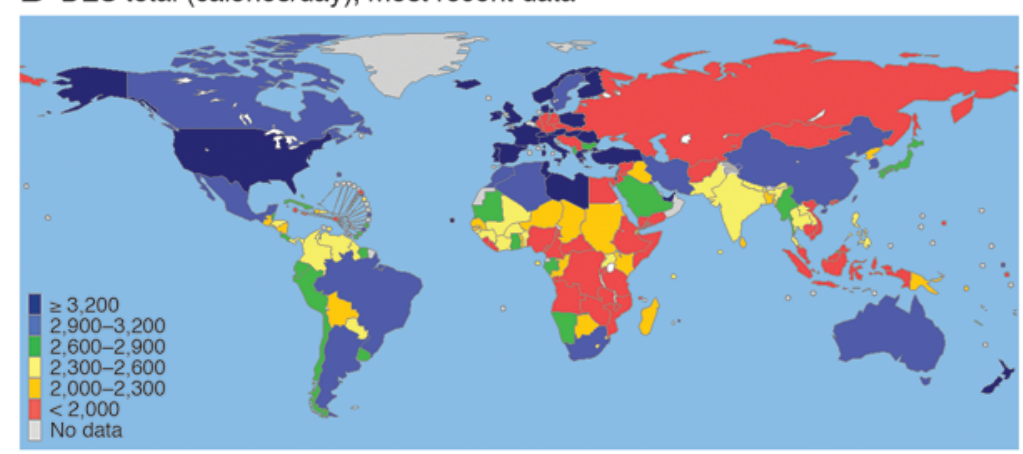

Worldwide estimates of average caloric intake in 1980 (A) and 2008 (B). Reproduced with permission from the WHO (8). DES, dietary energy supply. 

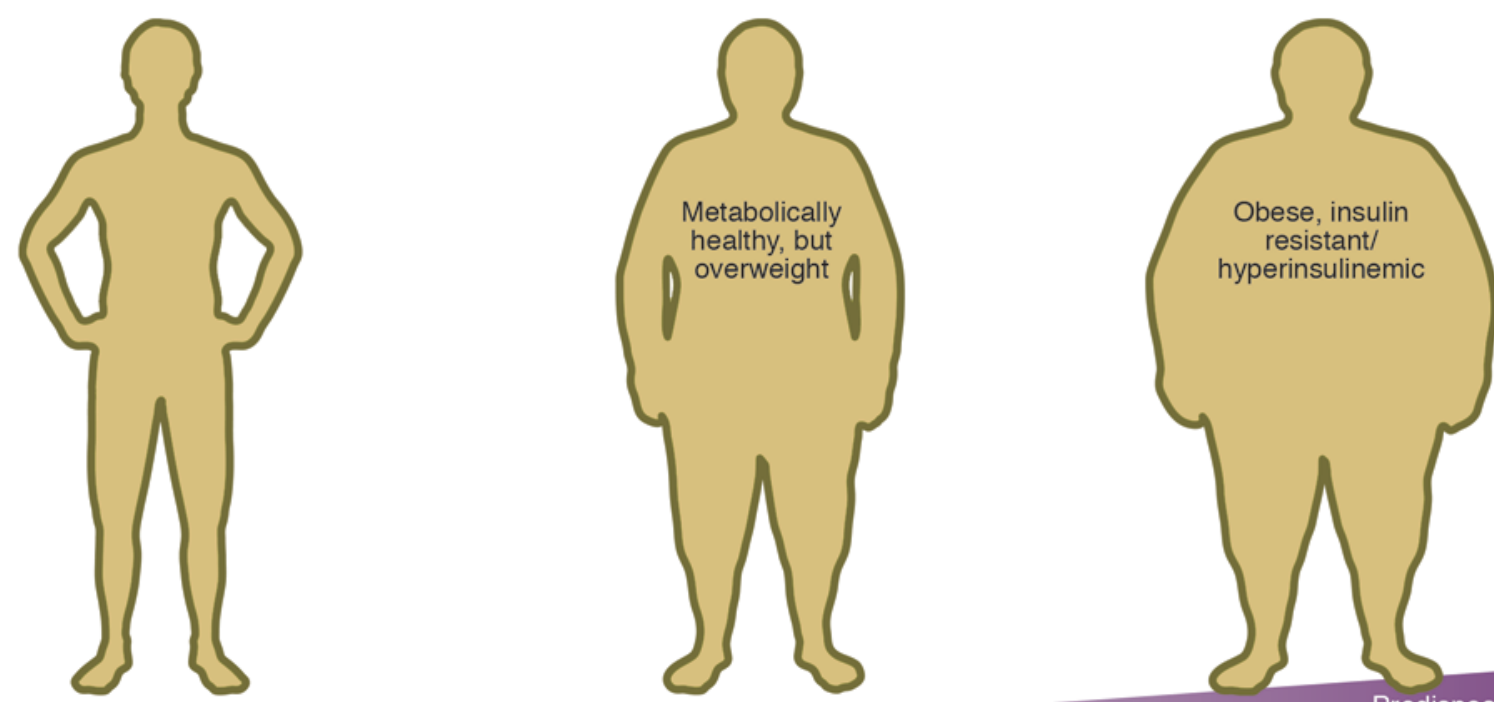

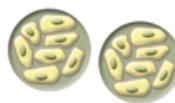

Pancreatic islets

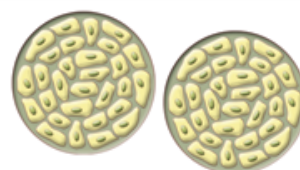

.

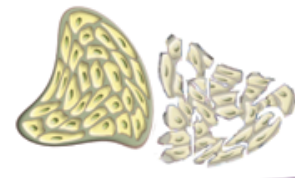

$\beta$ cell compensation NGT
Predisposition to $\beta$ cell failure/time
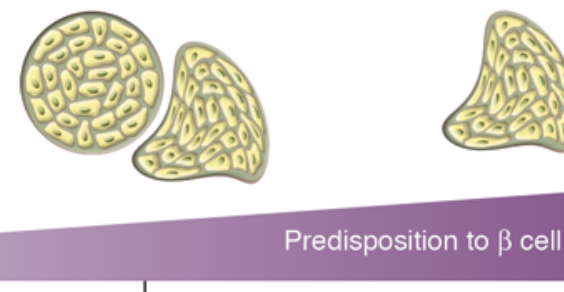

$\beta$ cell failure

T2D

\section{Figure 3}

Natural history of type 2 diabetes (T2D). Obesity results in an increase in $\beta$ cell mass and insulin secretion, which compensate for insulin resistance. Over time, $\beta$ cell compensation fails in some obese individuals, leading to progression from normal glucose tolerance (NGT) to impaired glucose tolerance (IGT) and, ultimately, type 2 diabetes associated with elevated blood glucose levels. Reproduced from the $\mathrm{JCl}$ (41).

leukocytes have profound effects on organ structure and function; thus immunomodulatory strategies may be beneficial in the treatment of type 2 diabetes and other complications of obesity.

Pancreatic $\beta$ cells secrete insulin, a key hormone that regulates blood glucose levels. Obesity is associated with insulin resistance, $\beta$ cell expansion, and hyperinsulinemia (Figure 3). In some patients, $\beta$ cell dysfunction and/or a loss of $\beta$ cell mass attenuates insulin production, leading to the development of diabetes mellitus. Genetics, nutrient toxicity, incretins, and growth factors have all been implicated in $\beta$ cell failure and diabetes. In this series, Seino et al. (37) explain the molecular mechanisms that control insulin secretion in normal versus obese individuals based on recent discoveries.

The discovery that the gastrointestinal tracts of obese humans and mice harbor different microbes from their lean counterparts sparked enormous speculation that manipulating gut microbes might provide a means for weight reduction (38). Here, Tilg and Kaser (39) discuss the regulation of gut microbes by genetic and environmental factors and how this affects the immune system of the host and may lead to the development of metabolic complications of obesity.
Finally, Huang et al. (40) review how circadian clocks align cellular biochemical processes and behavior. Disruption of circadian rhythms has profound effects on metabolism. Advances in understanding the molecular mechanisms linking circadian rhythms and metabolism disruption will provide novel insights and could suggest potential therapies for obesity, diabetes, cardiovascular disease, and other ailments associated with shift work, sleep deprivation, and other conditions that disrupt normal sleep-wake cycles.

\section{A way forward}

Our hope is that this series will spur greater interest in the basic and applied sciences pertaining to obesity and related diseases. A better understanding of cellular and molecular biology and pathophysiology will provide a framework for evidence-based treatment of obesity. Pharmacological approaches, surgery, and other treatments should complement the adoption of policies, societal practices, and population-wide interventions that promote healthier diets and decrease food consumption, collectively lessening the burden of obesity and its comorbidities. 


\section{Acknowledgments}

The Ahima laboratory is supported by funding from the NIH (grants RO1-DK062348, PO1-DK049210, P30-DK19525). The Obesity Review Series is supported in part by unrestricted educational grants from Merck \& Co. and the Life Sciences Institute of the University of Michigan.

1. Flegal KM, Carroll MD, Ogden CL, Curtin LR. Prevalence and trends in obesity among US adults, 1999-2008. JAMA. 2010;303(3):235-241.

2. WHO. Obesity: Preventing And Managing The Global Epidemic. Geneva, Switzerland: World Health Organization; 2000.

3. Stommel M, Schoenborn CA. Variations in BMI and prevalence of health risks in diverse racial and ethnic populations. Obesity (Silver Spring). 2010;18(9):1821-1816.

4. Ogden CL, Carroll MD, Curtin LR, McDowell MA, Tabak CJ, Flegal KM. Prevalence of overweight and obesity in the United States, 1999-2004. JAMA. 2006;295(13):1549-1555.

5. World Health Organization. Obesity and overweight. WHO Web site. http://www.who.int/mediacentre/factsheets/fs311/en/. Updated March 2011. Accessed April 28, 2011.

6. Finucane MM, et al. Global Burden of Metabolic Risk Factors of Chronic Diseases Collaborating Group (Body Mass Index). National, regional, and global trends in body-mass index since 1980: systematic analysis of health examination surveys and epidemiological studies with 960 country-years and 9.1 million participants. Lancet. 2011;377(9765):557-567.

7. de Onis M, Blössner M, Borghi E. Global prevalence and trends of overweight and obesity among preschool children. Am J Clin Nutr. 2010;92(5):1257-1264.

8. World Health Organization. Global Database on Body Mass Index. WHO Web site. http://apps.who. int/bmi/index.jsp. Accessed April 28, 2011.

9. Wing RR. Changing diet and exercise behaviors in individuals at risk for weight gain. Obes Res. 1995;3(3):277-282.

10. Sacks FM, et al. Comparison of weight-loss diets with different compositions of fat, protein, and carbohydrates. N Engl J Med. 2009;360(9):859-873.

11. Malik VS, Popkin BM, Bray GA, Després JP, Hu FB. Sugar-sweetened beverages, obesity, type 2 diabetes mellitus, and cardiovascular disease risk. Circulation. 2010;121(11):1356-1364.

12. Gross LS, Li L, Ford ES, Liu S. Increased consumption of refined carbohydrates and the epidemic of type 2 diabetes in the United States: an ecologic assessment. Am J Clin Nutr. 2004;79(5):774-779.

13. Bray GA. Soft drink consumption and obesity: it is all about fructose. Curr Opin Lipidol. 2010;21(1):51-57.
Address correspondence to: Rexford S. Ahima, Department of Medicine, Division of Endocrinology, Diabetes and Metabolism, and the Institute for Diabetes, Obesity and Metabolism, University of Pennsylvania School of Medicine, Philadelphia, Pennsylvania 19104, USA. Phone: 215.573.1872; Fax: 215.898.5408; E-mail: ahima@mail.med.upenn.edu.
14. Kestens Y, Daniel M. Social inequalities in food exposure around schools in an urban area. $A m J$ Prev Med. 2010;39(1):33-40.

15. Mavoa HM, McCabe M. Sociocultural factors relating to Tongans' and Indigenous Fijians' patterns of eating, physical activity and body size. Asia Pac J Clin Nutr. 2008;17(3):375-384.

16. Mehio Sibai A, Nasreddine L, Mokdad AH, Adra $\mathrm{N}$, Tabet M, Hwalla N. Nutrition transition and cardiovascular disease risk factors in Middle East and North Africa countries: reviewing the evidence. Ann Nutr Metab. 2010;57(3-4):193-203.

17. Smith DE, Lewis CE, Caveny JL, Perkins LL, Burke GL, Bild DE. Longitudinal changes in adiposity associated with pregnancy. The CARDIA Study. Coronary Artery Risk Development in Young Adults Study. JAMA. 1994;271(22):1747-1751.

18. Williamson DF, Madans J, Anda RF, Kleinman JC, Kahn HS, Byers T. Recreational physical activity and ten-year weight change in a US national cohort. Int J Obes Relat Metab Disord. 1993;17(5):279-286.

19. Hu FB, Li TY, Colditz GA, Willett WC, Manson JE. Television watching and other sedentary behaviors in relation to risk of obesity and type 2 diabetes mellitus in women. JAMA. 2003;289(14):1785-1791.

20. Robinson TN. Reducing children's television viewing to prevent obesity: a randomized controlled trial. JAMA. 1999;282(16):1561-1567.

21. Berrington de Gonzalez A, et al. Body-mass index and mortality among 1.46 million white adults. NEngl J Med. 2010;363(23):2211-2219.

22. Flegal KM, Graubard BI, Williamson DF, Gail $\mathrm{MH}$. Cause-specific excess deaths associated with underweight, overweight, and obesity. JAMA. 2007; 298(17):2028-2037.

23. Zheng W, et al. Association between body-mass index and risk of death in more than 1 million Asians. NEngl J Med. 2011;364(8):719-729.

24. Bhargava SK, et al. Relation of serial changes in childhood body-mass index to impaired glucose tolerance in young adulthood. N Engl J Med. 2004;350(9):865-875.

25. Tirosh A, et al. Adolescent BMI trajectory and risk of diabetes versus coronary disease. $N$ Engl J Med. 2011;364(14):1315-1325.

26. Guerrero RT, Paulino YC, Novotny R, Murphy SP. Diet and obesity among Chamorro and Filipino adults on Guam. Asia Pac J Clin Nutr. 2008;17(2):216-222.
27. El Rhazi K, Nejjari C, Zidouh A, Bakkali R, Berraho M, Gateau PB. Prevalence of obesity and associated sociodemographic and lifestyle factors in Morocco. Public Health Nutr. 2011;14(1):160-167.

28. Márquez-Sandoval F, Macedo-Ojeda G, Viramontes-Hörner D, Fernández Ballart J, Salas Salvadó J, Vizmanos B. The prevalence of metabolic syndrome in Latin America: a systematic review [published online ahead of print April 13, 2011]. Public Health Nutr. doi:10.1017/S1368980010003320.

29. Leibel RL. Molecular physiology of weight regulation in mice and humans. Int J Obes (Lond). 2008; 32(suppl 7):S98-S108.

30. Sjöström L, et al. Swedish Obese Subjects Study. Effects of bariatric surgery on mortality in Swedish obese subjects. N Engl J Med. 2007;357(8):741-752.

31. Ramachandrappa S, Farooqi IS. Genetic approaches to understanding human obesity. J Clin Invest. 2011;121(6):2080-2086.

32. Zhang Y, Proenca R, Maffei M, Barone M, Leopold L, Friedman JM. Positional cloning of the mouse obese gene and its human homologue. Nature. 1994; 372(6505):425-432.

33. Gautron L, Elmquist JK. Sixteen years and counting: an update on leptin in energy balance. J Clin Invest. 2011;121(6):2087-2093.

34. Sun K, Kusminski CM, Scherer PE. Adipose tissue remodeling and obesity. J Clin Invest. 2011; 121(6):2094-2101.

35. Greenberg AS, et al. The role of lipid droplets in metabolic disease in rodents and humans. J Clin Invest. 2011;121(6):2102-2110.

36. Lumeng CN, Saltiel AR. Inflammatory links between obesity and metabolic disease. J Clin Invest. 2011; 121(6):2111-2117.

37. Seino S, Shibasaki T, Minami K. Dynamics of insulin secretion and the clinical implications for obesity and diabetes. JClin Invest. 2011;121(6):2118-2125.

38. Goodman AL, Gordon JI. Our unindicted coconspirators: human metabolism from a microbial perspective. Cell Metab. 2010;12(2):111-116.

39. Tilg H, Kaser A. Gut microbiome, obesity, and metabolic dysfunction. J Clin Invest. 2011; 121(6):2126-2132.

40. Huang W, Ramsey KM, Marcheva B, Bass J. Circadian rhythms, sleep, and metabolism. J Clin Invest. 2011;121(6):2133-2141.

41. Prentki M, Nolan CJ. Islet Beta cell failure in type 2 diabetes. J Clin Invest. 2006;116(7):1802-1812. 